OPEN ACCESS

Edited by:

Jesús Malo,

Universitat de València, Spain

Reviewed by:

David A. Leopold

National Institutes of Health $(\mathrm{NIH})$,

United States

Andrew Biewener,

Harvard University, United States

*Correspondence:

Douglas R. Wylie

mdwylie@ualberta.ca

Specialty section:

This article was submitted to

Perception Science,

a section of the journal

Frontiers in Neuroscience

Received: 20 July 2017 Accepted: 21 March 2018

Published: 09 April 2018

Citation:

Wylie DR, Gutiérrez-Ibáñez C,

Gaede AH, Altshuler DL and Iwaniuk AN (2018) Visual-Cerebellar

Pathways and Their Roles in the

Control of Avian Flight.

Front. Neurosci. 12:223.

doi: 10.3389/fnins.2018.00223

\section{Visual-Cerebellar Pathways and Their Roles in the Control of Avian Flight}

\author{
Douglas R. Wylie ${ }^{1 *}$, Cristián Gutiérrez-lbáñez ${ }^{1}$, Andrea H. Gaede ${ }^{1,2}$, Douglas L. Altshuler ${ }^{2}$ \\ and Andrew N. Iwaniuk ${ }^{3}$
}

${ }^{1}$ Neuroscience and Mental Health Institute, University of Alberta, Edmonton, AB, Canada, ${ }^{2}$ Department of Zoology, University of British Columbia, Vancouver, BC, Canada, ${ }^{3}$ Department of Neuroscience, Canadian Centre for Behavioural Neuroscience, University of Lethbridge, Lethbridge, AB, Canada

In this paper, we review the connections and physiology of visual pathways to the cerebellum in birds and consider their role in flight. We emphasize that there are two visual pathways to the cerebellum. One is to the vestibulocerebellum (folia IXcd and X) that originates from two retinal-recipient nuclei that process optic flow: the nucleus of the basal optic root (nBOR) and the pretectal nucleus lentiformis mesencephali (LM). The second is to the oculomotor cerebellum (folia VI-VIII), which receives optic flow information, mainly from LM, but also local visual motion information from the optic tectum, and other visual information from the ventral lateral geniculate nucleus (Glv). The tectum, LM and Glv are all intimately connected with the pontine nuclei, which also project to the oculomotor cerebellum. We believe this rich integration of visual information in the cerebellum is important for analyzing motion parallax that occurs during flight. Finally, we extend upon a suggestion by Ibbotson (2017) that the hypertrophy that is observed in LM in hummingbirds might be due to an increase in the processing demands associated with the pathway to the oculomotor cerebellum as they fly through a cluttered environment while feeding.

Keywords: cerebellum, optic flow processing, lentiformis mesencephali, pontine nuclei, motion parallax, flight control

Gibson (1954) emphasized that self-motion results in optic flow across the entire retina and that such visual information can be used to control posture and locomotion. One of the classic illustrations from Gibson (1979) to exemplify this is reproduced in Figure 1, which shows the optic flowfield resulting from a bird in flight. Despite widespread evidence supporting the importance of optic flow in modulating posture and locomotion across vertebrate species (e.g., Lee, 1980; Warren et al., 2001), it is only recently that a few studies (Bhagavatula et al., 2011; Goller and Altshuler, 2014; Schiffner and Srinivasan, 2015; Dakin et al., 2016; Ros and Biewener, 2016) have explicitly demonstrated that manipulation of the optic flow field can affect flight behavior of birds (Lee and Reddish, 1981; but see, Davies and Green, 1990; Lee et al., 1991, 1993; Eckmeier et al., 2008). Optic flow is analyzed by specialized visual pathways in the avian brain, which originate from two retinal-recipient nuclei: the nucleus of the basal optic root (nBOR) of the Accessory Optic System, and the pretectal nucleus lentiformis mesencephali (LM). Neurons in LM and nBOR have very large receptive fields and exhibit direction-selectivity in response to optic flow stimuli (Burns and Wallman, 1981; Morgan and Frost, 1981; Winterson and Brauth, 1985; Wylie and Crowder, 2000). Such responses are unique to LM and nBOR cells, as other motion-sensitive cells in the visual system respond best to small object-like stimuli, and have large-inhibitory surrounds such that they do not respond to optic flow (Frost et al., 1990). Although LM and nBOR have been implicated 


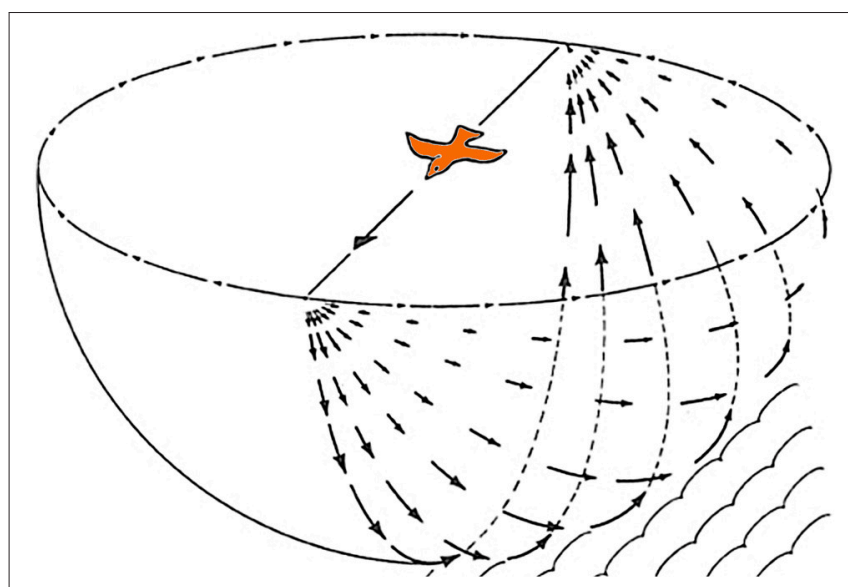

FIGURE 1 | The optic flowfield during forward flight. Adapted from Gibson (1979).

in the generation of the optokinetic response for retinal image stabilization (Fite et al., 1979; Gioanni et al., 1983a,b), their involvement in the visual control of flight has yet to be demonstrated. However, Iwaniuk and Wylie (2007) noted that the LM was 2 to $5 \mathrm{X}$ larger in hummingbirds compared to other birds (Figures 2A,B). LM was also enlarged in species that occasionally hover, such as the eastern spinebill (Acanthorhynchus tenuirostris), a nectarivorous Australian songbird. As hovering represents a specialized case of stabilization, Iwaniuk and Wylie (2007) postulated that the hypertrophy of the LM was to facilitate hovering. Subsequently, Gaede et al. (2017) recorded from the LM in hummingbirds and noted their response properties to largefield stimuli were quite different from other birds. nBOR and LM have extensive direct and indirect connections with the cerebellum (Clarke, 1977; Brecha et al., 1980; Gamlin and Cohen, 1988a; Wylie et al., 1997; Pakan and Wylie, 2006), which is well established to be involved in motor control (Ito, 1984). Pakan and Wylie (2006) noted that $\mathrm{nBOR}$ and LM give rise to two optic flow pathways to the cerebellum; to the posterior part, folia IXcd and X, which collectively are know as the vestibulocerebellum (VbC), and to the oculomotor cerebellum, which is comprised of folia VI-VIII (see below). In this paper, we will expand upon the proposed role of the LM and visual cerebellar pathways in avian flight by exploring several questions: What other visual nuclei should show hypertrophy in concert with the LM? Which part of the LM is hypertrophied in hummingbirds? And finally, is the expansion of the LM in hummingbirds driven by the visual demands of behaviors other than hovering, as preciously suggested?

\section{RESPONSE PROPERTIES OF NEURONS IN NBOR AND LM}

Neurons in nBOR and LM are ideally suited for the analysis of optic flow because they have large receptive fields averaging about $60^{\circ}$ in diameter with some encompassing the entire monocular visual field. These neurons are directionally selective in response to large stimuli, such as random dot patterns, checkerboards, and gratings. The response properties of nBOR neurons have been investigated in chickens (Gallus gallus, Burns and Wallman, 1981) and pigeons (Morgan and Frost, 1981; Columba livia, Gioanni et al., 1984; Wylie and Frost, 1990), and the responses are essentially identical. With respect to direction preference, neurons that prefer upward, downward and backward (i.e., nasal-to-temporal) motion are about equally abundant in nBOR, but fewer (5-10\%) prefer forward (i.e., temporal-to-nasal) motion (Frost et al., 1990). With respect to stimulus speed, neurons are broadly tuned, but the majority $(\sim 75 \%)$ prefer slow velocities $\left(<5^{\circ} / \mathrm{s}\right)$ (Burns and Wallman, 1981; Crowder et al., 2003). Data from chickens, pigeons and zebra finches (Taeniopygia guttata) suggest that the LM is complementary to the nBOR regarding direction preference. In LM, there is a clear directional bias to forward motion: about half the neurons prefer motion in this direction and neurons that prefer upward, downward and backward motion are equally represented (McKenna and Wallman, 1985b; Winterson and Brauth, 1985; Wylie and Frost, 1996; Wylie and Crowder, 2000; Gaede et al., 2017) (Figure 2D). The bias toward neurons that prefer forward motion has also been found in the homologs of the LM in amphibians, reptiles, and mammals (Collewijn, 1975; Katte and Hoffmann, 1980; Fan et al., 1995). With respect to speed, as in nBOR, LM neurons are broadly tuned, but most (about $65 \%$ ) prefer faster stimuli $\left(>5^{\circ} / \mathrm{s}\right.$ and up to $250^{\circ} / \mathrm{s}$ ). Almost all $(>95 \%)$ of the LM neurons that prefer slower speeds prefer forward motion. Stated another way, there are two groups of LM neurons: (i) slow neurons that prefer forward motion; and (ii) fast neurons that prefer upward downward and backward motion (Wylie and Crowder, 2000) (see Figure 2F). There is also evidence suggesting that there is a separation of directional response types within LM. Winterson and Brauth (1985) noted that most cells in the LM parvocellularis, now known as the lateral LM (LMl; Gamlin and Cohen, 1988b) preferred forward motion, whereas cells that prefer upward, downward, backward and forward motion are found in LM magnocellularis, now known as the medial LM (LMm, Gamlin and Cohen, 1988b). This is important because the LMm and LMl project to different parts of the cerebellum (see below, Pakan and Wylie, 2006).

\section{THE LM IN HUMMINGBIRDS}

As mentioned above, LM is hypertrophied in hummingbirds (Iwaniuk and Wylie, 2007). In a more recent study, Gaede et al. (2017) recorded from the LM of Anna's hummingbird (Calypte anna) and noted that the neuronal responses to largefield visual stimuli differed in hummingbirds compared with other bird species. First, a directional bias to forward motion was not found, rather all directions were represented equally (Figure 2C). Second, LM neurons in hummingbirds were tightly tuned to stimulus velocity, and mainly to speeds higher than $48^{\circ} / \mathrm{s}$ (Figure 2E). In this regard, hummingbirds could be regarded as visual "velocity specialist," forgoing coarse coding common in perceptual systems for a specificity code seen in other sensory specialists, such as neurons tuned for auditory space in owls 

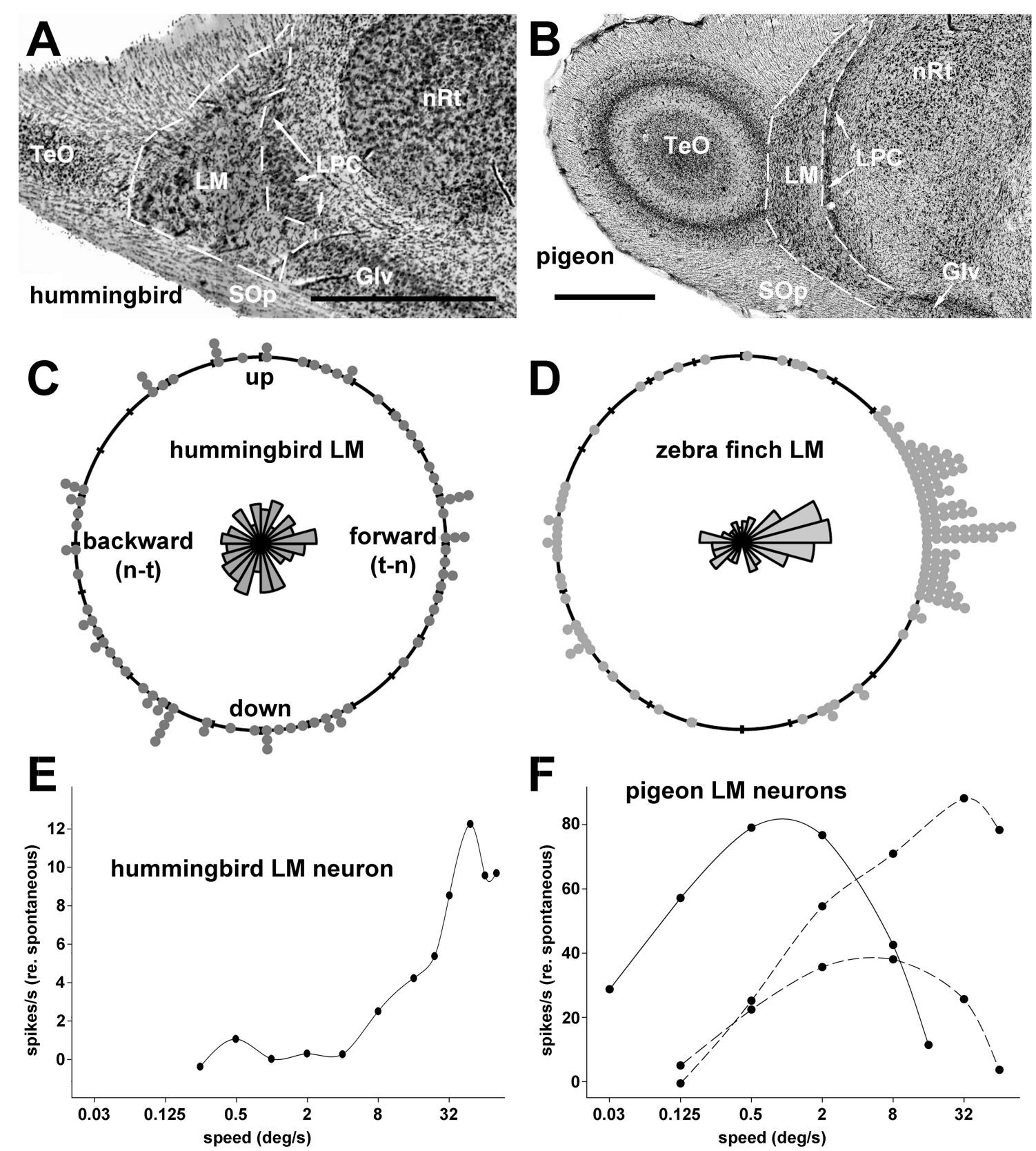

FIGURE 2 | Coronal sections through the pretectal nucleus lentiformis mesencephali (LM) in a hummingbird (Doryfera ludoviciae) (A, from Iwaniuk and Wylie, 2007, with permission) and a pigeon (Columba livia) (B). (C,D) Respectively show the direction preferences of LM neurons in Anna's hummingbird (Calypte anna) and zebra finch (Taeniopygia guttata) (from Gaede et al., 2017, with permission). (E) Shows the speed tuning curve for a LM neuron in a Anna's hummingbird (from the data set of Gaede et al., 2017). The visual stimuli were largefield random dot patterns moving in the preferred direction. (F) Shows the speed tuning for $3 \mathrm{LM}$ neurons in pigeon: (from the data set of Crowder et al., 2003). One is a "slow" neuron that preferred forward (nasal to temporal) motion (solid line), whereas the other two are "fast" neurons that preferred backward (lower dashed line) and downward (upper dashed line) motion. The visual stimulus were largefield sine wave gratings of an effective spatial frequency ( 1 cycle per degree [cpd] for the slow neuron, $0.25 \mathrm{cpd}$ for the fast neurons) drifting in the preferred directions. Other abbreviations: Glv, ventral lateral geniculate nucleus; LPC, nucleus laminaris precommissuralis; nRt, nucleus rotundas; TeO, optic tectum; SOp, stratum opticum; t-n, temporal to nasal; n-t, nasal to temporal. Scale bars; $0.5 \mathrm{~mm}$ in (A) $1 \mathrm{~mm}$ in (B).

(Konishi, 2003; Lesica et al., 2010). Insofar as Winterson and Brauth (1985) noted that LMl contained neurons that prefer forward motion, whereas neurons representing all directions of motion, (which prefer faster speeds), were found in LMm, we speculate that the hypertrophy of the LM in hummingbirds may be largely due to an expansion of the LMm. 

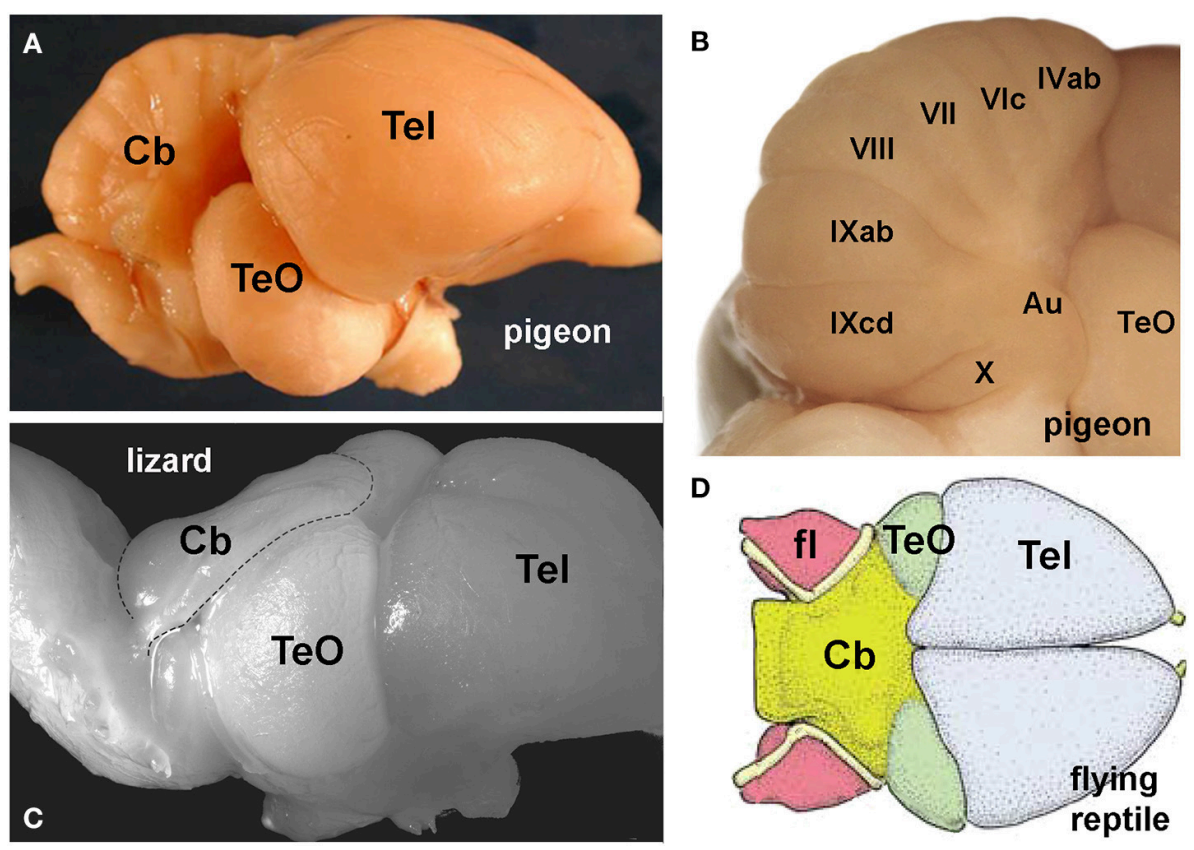

FIGURE 3 | (A) Shows a lateral view of the pigeon brain, to emphasize the relatively large size of the cerebellum (Cb). (B) Shows the numbered folia of the posterior lobe. The vestibulocerebellum ( VbC) includes folia IXcd and X, and the laterally protruding auricle (Au). (C) Shows a lateral view of the brain of a dragon lizard (Ctenophorus nuchalis) emphasizing the small underdeveloped Cb) (from Wylie et al., 2016, with permission). (D) Shows a dorsal view of the brain (endocast) of a flying reptile (Rhamphorhynchus muensteri) showing the large cerebellum (yellow) and the cerebellar flocculus (fl) (from Witmer et al., 2003, with permission). Other abbreviations: TeO, optic tectum; Tel, telencephalon.

\section{THE CEREBELLUM AND FLIGHT}

It is not unreasonable to assume that flight demands acute multisensory integration and sophisticated motor control. The cerebellum is large and well developed in birds (Figure 3A) and as the cerebellum is traditionally implicated in motor control (Ito, 1984) and is clearly a site of multisensory integration (Paulin, 1993; Bower, 1997) it is not surprising that it is thought to be important for flight (Kornhuber, 1974). Husband and Shimizu (2001) noted that the cerebellum is much larger in birds compared to non-avian reptiles (Figures 3A-C). Witmer et al. (2003) examined gross brain morphology from the endocasts of extinct flying reptiles and noted that there was a large cerebellum, in particular, the flocculus (fl) of the $\mathrm{VbC}$ (Figure 3D). However, Walsh et al. (2013) urge caution in this regard, because they found no correlation between the flying behavior and the size of the flocculus in extant birds, and large cerebella are also present in several bird-like non-flying dinosaurs. Nonetheless, Walsh et al. acknowledge that the evolution of the large cerebellum may have rendered birds flight ready. Finally, Feenders et al. (2008) used the expression of immediate-early genes as an indicator of neural activity during various behaviors. During flight, activity was evident, especially in folia VI and IXcd. As mentioned, optic flow pathways to the cerebellum in birds are precisely to these two areas, the oculomotor cerebellum (folia VI-VII) and the VbC (folia IXcd and X, see below, Figure 4). Thus, several lines of evidence suggest a key role for the cerebellum in avian flight.

\section{THE OPTIC FLOW PATHWAY TO THE VESTIBULOCEREBELLUM}

The first optic flow pathway to the cerebellum is to the $\mathrm{VbC}$, folia IXcd and X (Figure 4A). The VbC is divided into the lateral flocculus (fl), which includes the lateral protrusion of the cerebellum known as the auricle (see Figure 3B), and the medial $\mathrm{VbC}$ comprised of the ventral uvula and nodulus. Optic flow information reaches the $\mathrm{VbC}$ directly, as mossy fibers (MFs) that originate from neurons in both $\mathrm{nBOR}$ and $\mathrm{LM}$ and terminate in folium IXcd, but not X (see Figures 4A,B for details and the relative position of each nuclei in the brain of the pigeon) (Clarke, 1977; Brecha et al., 1980; Gamlin and Cohen, 1988a). The majority $(\sim 75 \%)$ of the LM projection is from LMl (Pakan and Wylie, 2006). nBOR and LM also project indirectly to the VbC via the medial column of the inferior olive ( $\mathrm{mcIO})$, whose cells ascend to the $\mathrm{VbC}$ as climbing fibers (CFs) (Arends and Voogd, 1989; Lau et al., 1998; Wylie, 2001). This indirect projection from the LM arises from fusiform cells that lie in a thin strip along the border between LMm and LMl (Pakan et al., 2006). These two different pathways(CF and MF),also originate from cells with different speed preferences: the CF pathway originates from the slow cells in the nBOR and LM, whereas the MF pathway is fed by both slow and fast cells in nBOR and LM (Winship et al., 2005). This CF pathway to the VbC has been studied in detail in several mammalian species (e.g., Graf et al., 1988), and is critical for retinal image stabilization and the modification of the 

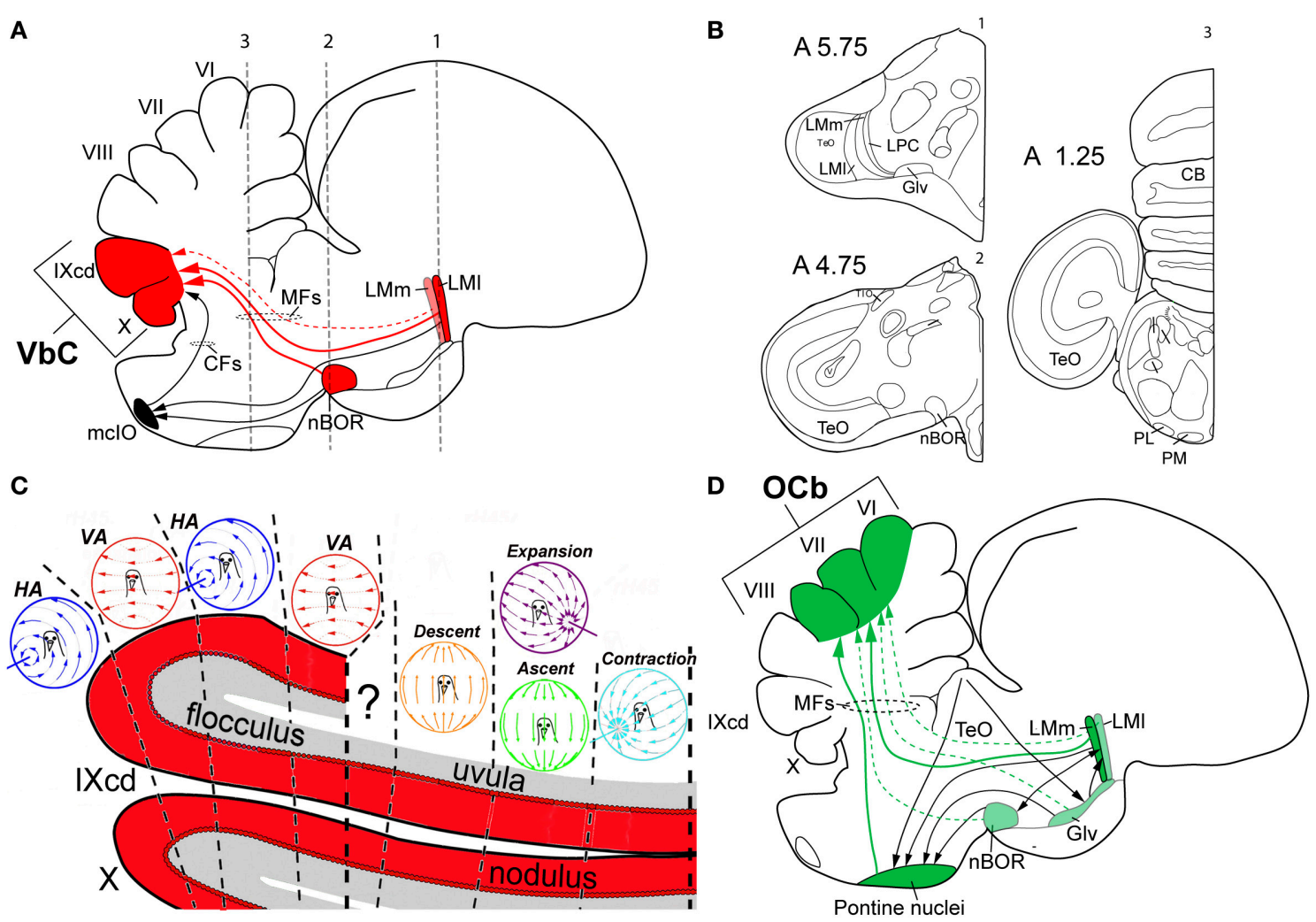

FIGURE 4 | Visual cerebellar pathways in birds. (A) Shows in red the optic flow pathways from the nucleus of the basal optic root (nBOR) and pretectal nucleus lentiformis mesencephalic (LM) to the vestibulocerebellum ( $\mathrm{VbC}$; folia IXcd and X), black arrows show projections to the medial column of the inferior olive (mclO). (B) Shows schematic drawings of coronal sections at three different anteroposterior levels (1-3 in $\mathbf{A}$ ) of the pigeon's brain to show the relative position of the different nuclei involve in visual pathways to the cerebellum in birds. Coordinates in the pigeon brain atlas of Karten and Hodos (1967) are shown. Adapted from Karten and Hodos (1967). (C) Shows the sagittal optic flow "zones" in the VbC. (D) Shows in green and black the extensive pretecto-ponto-cerebellar connectivity to the oculomotor cerebellum (OCb, folia VI-VII). The larger arrows with solid lines represent heavier projections, whereas the smaller arrows with dotted lines represent weaker projections. See text for details. Other abbreviations: CFs, climbing fibers; Glv, ventral lateral geniculate nucleus; HA, horizontal axis (neurons); LMl, lateral LMm, medial LM; MFs, mossy fibers; PL, lateral pontine nucleus; PM, medial pontine nucleus; VA, vertical axis (neurons).

vestibular ocular reflex by visual-information (Ito, 1998). This is a highly conserved pathway, as the physiology and anatomy of this CF pathway to the flocculus is strikingly similar in birds and mammals (Voogd and Wylie, 2004).

The CFs give rise to the complex spike activity (CSA) of Purkinje cells in mammals, birds and likely other vertebrates (Eccles et al., 1966; Wylie and Frost, 1991). Depicted in Figure 4C, the VbC in birds is organized into several optic flow "zones" (Voogd and Bigaré, 1980), which lie in the sagittal plane and cut across IXcd and X. The CSA in the flocculus responds most strongly to rotational optic flow about either the vertical axis (VA neurons) or an horizontal axis oriented $45^{\circ}$ to the midline (HA neurons) (Wylie and Frost, 1993). In pigeon, there are two VA zones interdigitated with two HA zones (Winship and Wylie, 2003). In the uvula/nodulus, the CSA responds most strongly to optic flow resulting from translation (Wylie et al., 1993). As depicted in Figure 4C, there are four response types organized into three sagittal zones. In the most medial zone, CSA responds most stronglyto optic flow resulting from translation backwards along an horizontal axis $45^{\circ}$ to the midline such that there is a focus of contraction at $45^{\circ}$ contralateral azimuth (contraction neurons). Medial to this is a zone where the CSA responds most strongly to optic flow resulting from either (i) forward translation along an horizontal axis $45^{\circ}$ to the midline such that there is a focus of expansion at $45^{\circ}$ ipsilateral azimuth, or (ii) upward translation along the vertical axis. Finally, lateral to this is a zone where the CSA responds to the optic flow resulting from downward translation along the vertical axis (Wylie et al., 1998; Graham and Wylie, 2012). Thus, the VbC is well suited to analyze the optic flow resulting from self-translation and self-rotation as birds fly through the world. This is combined with vestibular information derived from separate end organs for analyzing rotation (semicircular canals) and translation (otolith organs) (Pakan et al., 2008).

\section{THE OPTIC FLOW PATHWAY TO THE OCULOMOTOR CEREBELLUM}

A second optic flow pathway to the cerebellum of birds is to folia VI-VIII of the posterior lobe, which are collectively known 
as the "oculomotor cerebellum" (OCb; Voogd and Barmack, 2006). This region of the cerebellum has been implicated in flight insofar as the "strong fliers" as defined by Larsell (1967) tend to have a large posterior lobe, in particular folia VI and VII, and these folia are significantly smaller in flightless birds (Iwaniuk et al., 2007). The LM and nBOR project as MFs to folia VI-VIII (Clarke, 1977; Brecha et al., 1980; Figure 4D). The projection from $\mathrm{nBOR}$ is relatively small, but the projection from LM is massive and originates mainly in LMm $(\sim 75 \%)$ (Pakan and Wylie, 2006). As shown in Figure 4D, folia VI-VII are part of a much more extensive visuo-motor network that incorporates visual information from several indirect sources. These folia also receive heavy MF projections from the medial and lateral pontine nuclei (MP, LP) (Brodal et al., 1950; Freedman et al., 1975; Clarke, 1977; Pakan and Wylie, 2006). The pontine nuclei in turn receive projections from several retino-recipient sources including nBOR (although this is minor; Wylie et al., 1997), the optic tectum, which sends projection mainly to LP (Hunt and Künzle, 1976; Wylie et al., 2009), and LM, which projects mostly to MP (Clarke, 1977; Gamlin and Cohen, 1988a), and Glv (Marín et al., 2001). Glv itself receives input from the optic tectum (Hunt and Künzle, 1976; Wylie et al., 2009; Vega-Zuniga et al., 2014), and in turn projects heavily to LM, mainly to LMm (Vega-Zuniga et al., 2016), providing some interconnectivity among these retinorecipient regions before sending efferents to MP and folia VI-VIII. Because this system receives direct and indirect input from several visual regions, it is well suited for integrating different types of visual information. Whereas the LM is concerned with optic flow, neurons in the tectum respond to small moving stimuli (Frost and Nakayama, 1983; Frost et al., 1990). The exact nature of visual processing in Glv remains elusive, however, electrical stimulation of the Glv elicits discrete, precise orienting head movements (Vega-Zuniga et al., 2011). All of this information is integrated in the pontine nuclei and folia VI-VIII, but for what purpose?

The integration of local motion and optic flow information in primate visual cortex is implicated in "steering" to avoid obstacles during locomotion through cluttered environments (Page and Duffy, 2008; Elder et al., 2009). Similarly, Hellmann et al. (2004) suggested that the tecto-pontine pathway in birds is involved in avoidance behavior. Thus, perhaps this network integrating optic flow and local motion signals is important for obstacle avoidance as birds fly through cluttered environments. For example, during translation, a radial optic flow pattern would result, which would be detected by neurons in LM and nBOR. In addition, selfmotion would cause motion parallax of stationary objects at different depths. Such local motion relative to the background, is the ideal stimulus to activate deep tectal cells (Frost and Nakayama, 1983), which project to the pontine nuclei (Hellmann et al., 2004). This combination of local motion and optic flow during self-translation would then be analyzed by the pretecto-ponto-cerebellar system to folia VI-VIII (Figure 4D), allowing a flying bird to then adjust its direction and velocity accordingly.

\section{OPTIC FLOW PATHWAYS TO THE CEREBELLUM OF MAMMALS}

The visual pathways that convey optic flow information to the cerebellum of mammals are similar to those in birds and have been studied extensively (Simpson, 1984; Voogd and Barmack, 2006). A detailed review of this literature is beyond the scope of this review but a brief summary follows. As in mammals (and other vertebrates), optic flow is analyzed in specialized optic pathways, which begin in two retinorecipient nuclei, the medial and dorsal terminal nuclei of the AOS (homolog to nBOR of birds) and the nucleus of the optic tract (NOT; homolog to LM of birds). These two nuclei are also highly conserved among other vertebrates (Simpson, 1984; McKenna and Wallman, 1985a). Similar to birds, in mammals two regions of the cerebellum ultimately receive visual inputs from these two nuclei, the oculomotor cerebellum (folia VI-VIII) and the VbC (Reviewed in Voogd and Barmack, 2006). However, in contrast to birds, in most mammals optic flow information does not reach the cerebellum directly as mossy fibers from the terminal nuclei and NOT, but rather indirectly through different relay nuclei (see Simpson, 1984; Pakan et al., 2010). As in birds, these nuclei do project to regions of the inferior olive which then projects as climbing fibers to the $\mathrm{VbC}$ (Giolli et al., 2006). In the case of the oculomotor cerebellum of mammals, visual projections arise from the pontine nuclei, which like in birds receive projections from the accessory optic system, the NOT, the ventral geniculate, pretectum and the superior colliculus (reviewed in Voogd and Barmack, 2006). The existence of very similar optic flow pathway to the cerebellum of mammals strongly suggest that these are ancestral characters of at least all land vertebrates, and that like the expansion of the cerebellum, they precede the evolution of flight in birds.

\section{CONCERTED EVOLUTION OF THE LM WITH OTHER VISUAL NUCLEI}

Jerison's principle of proper mass states that an increase in the size of a brain nucleus is associated with an increase in the processing power needed to meet behavioral requirement (Jerison, 1973). The classic example is the increased size of the hippocampus in food caching birds (Sherry et al., 1989). Iwaniuk and Wylie (2007) suggested the increase in size of the LM in hummingbirds and other birds is related to an increased need for stabilization during hovering. Although through evolution a single brain nucleus can increase (or decrease) in size, so called "mosaic evolution," more often large parts of the brain or whole systems evolved together: "concerted evolution" (Striedter, 2005). Gutiérrez-Ibáñez et al. (2014) showed in birds that an increase in size of one visual nucleus is associated with increased in other visual nuclei, but the strength of the correlations varied greatly across pairs of visual nuclei. This is shown in Figure 5, where we show the correlation of the relative sizes of various visual nuclei across 77 species of birds (data are from GutiérrezIbáñez et al. (2014), plus unpublished measurements of pontine 


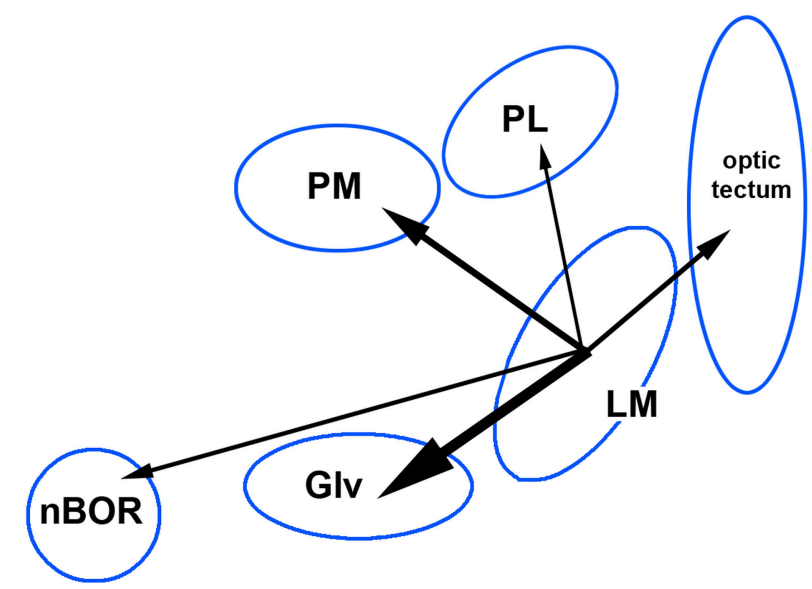

FIGURE 5 | Correlations of the relative size of the pretectal nucleus mesencephali (LM) with the medial and lateral pontine nuclei (PM, PL) and other visual nuclei including the nucleus of the basal optic root (nBOR), the ventral lateral geniculate nucleus (Glv) and the optic tectum. The size of the arrows represents the strength of the correlation. These data are from Gutiérrez-Ibáñez et al. (2014); Gutierrez-Ibanez et al. (2017). See text for details.

nuclei). Note that while the correlation between the LM and $\mathrm{nBOR}$ is of a significant magnitude (0.25), the correlation is higher between the LM and PM (0.39) and highest between LM and Glv (0.62). The correlations between LM and PL and LM and the optic tectum are also comparatively low (0.2 and 0.29, respectively). The correlation between PM and Glv is also high (0.54). Thus, the LM tends to increase in size with Glv and the PM, more so than other structure shown in Figures 4A,D. This covariation likely reflects the aforementioned connections among these nuclei and that these regions evolve in a correlated fashion due to increased information processing requirements of one or all nuclei. Based on our findings in hummingbirds, we propose that LM may be the region undergoing direct selection and that the associated changes in Glv and PM are through correlated evolution, as a result of increasing input and output requirements of LM. This preliminary hypothesis could be tested using evolutionary path analysis (von Hardenberg and GonzalezVoyer, 2013) to tease apart directionality of correlated size changes.

\section{HYPERTROPHY OF THE LM FOR THE ANALYSIS OF OPTIC FLOW AND MOTION PARALLAX}

We have established that LM is enlarged in hummingbirds and, as depicted in Figure 4, that the LM feeds two cerebellar pathways. One is to the $\mathrm{VbC}$ (IXcd) that arises mainly from LMl and also from nBOR (Figure 4A). The second is to folia VI-VIII where there is an integration of optic flow signals from LMm and local motion from a tecto-pontine circuit and involving Glv (Figure 4D). We suggest that the hypertrophy of LM in hummingbirds may be due to an expansion LMm given the following facts.

(i) Across birds, an increase in the size of the LM is associated with increases in the size of Glv and the PM, more so than nBOR (Figure 5).

(ii) Related, the Glv projects mainly to LMm as opposed to LMl (Vega-Zuniga et al., 2016).

(iii) Some neurons in LM prefer fast speeds, whereas others prefer slow speeds. Invariably, the slow neurons prefer temporal-to-nasal motion, whereas the fast neurons prefer various direction of motion (Wylie and Crowder, 2000). As most neurons in LMl prefer temporal-tonasal motion, one can infer that the fast and slow neurons are more associated with LMm and LMl, respectively.

(iv) Xiao and Frost (2013) showed that the fast LM neurons respond best to motion parallax.

(v) Finally, Gaede et al. (2017) showed that neurons in LM of hummingbirds respond differently than other species in two respects. First, there was no bias to neurons that prefer temporal-to-nasal motion, as has been observed in the LM of other birds. Second, the LM neurons in hummingbirds preferred faster velocities than other birds. Indeed, the LM neurons in hummingbirds were rather tightly tuned to fast velocities. This bias away from neurons that prefer temporal-to-nasal motion, and toward fast velocities suggests that the hummingbird LM is processing stimuli typically processed by the LMm in pigeons.

As previously mentioned, Iwaniuk and Wylie (2007) suggested that the hypertrophy of LM in hummingbirds is driven by the increased need to use optic flow to drive the optokinetic response, which facilitates stabilization during hovering. This argument was supported by an expansion of LM in other birds capable of hovering (e.g., kingfishers), although the increase in the size of LM in these species was smaller than in hummingbirds. However, Ibbotson (2017) suggested that the selectivity of hummingbird LM neurons to fast velocities may be related to flying in dense vegetation, as images that are close to the animal will move very quickly across the retina. The five points laid out above suggest that the expansion of LM in hummingbirds could be driven by a differential increase in the size of LMm, where neurons tend to be tuned to higher speeds (Winterson and Brauth, 1985) but also motion parallax, which would occur as they fly through cluttered environments. As Iwaniuk and Wylie (2007) measured LM as whole, there is no evidence that the expansion of LM in hummingbirds is due to a relative increase in the size of LMm vs. LMl. It would be interesting to see if this is the case and if hummingbirds show an increase in the magnitude of the projection from the LMm to the oculomotor cerebellum. In summary, the hypertrophy of LM in hummingbirds may not be related to hovering alone, but could also be related to an increase in the processing demands associated with the pathway to the oculomotor cerebellum as they fly through a cluttered environment while feeding. 


\section{CONCLUSIONS}

In this paper we have reviewed evidence that visual cerebellar pathways are involved in the control of flight. Moreover, there are two pathways involved: a pathway to the $\mathrm{VbC}$ involved in the processing of optic flow resulting from self-translation and selfrotation, and a pathway to folia VI-VIII that integrates optic flow and local motion information such as that which occurs during self-motion through cluttered environments. These pathways are fed by different parts of the LM, LMl, and LMm, that have different response properties to optic flow stimuli. Further, we suggest that the hypertrophy of the LM observed in hummingbirds may be driven more so by an hypertrophy of the LMm to support an increased demand of integrating local motion and optic flow signals to process motion parallax in cluttered environment. Hummingbirds spend much of their time feeding, and clearly they will be faced with optic flow and motion parallax as they forage through a patch of flowers. In this respect, we completely concur with Ibbotson (2017) who stated: "It is likely

\section{REFERENCES}

Arends, J. J. A., and Voogd, J. (1989). "Topographic aspects of the olivocerebellar system in the pigeon," in Experimental Brain Research Series 17: The Olivocerebellar System in Motor Control, ed P. Stata (Heidelberg; Berlin: Springer-Verlag), 52-57.

Bhagavatula, P. S., Claudianos, C., Ibbotson, M., and Srinivasan, M. (2011). Optic flow cues guide flight in birds. Curr. Biol. 21, 1794-1799. doi: $10.1016 /$ j.cub.2011.09.009

Bower, J. M. (1997). "Is the cerebellum sensory for motor's sake, or motor for sensory's sake: the view from the whiskers of a rat?," in Progress in Brain Research, eds I DeZeeuw Chris, P. Strata, and J. Voogd (Amsterdam: Elsevier Science), 463-496.

Brecha, N., Karten, H. J., and Hunt, S. P. (1980). Projections of the nucleus of the basal optic root in the pigeon: an autoradiographic and horseradish peroxidase study. J. Comp. Neurol. 189, 615-670.

Brodal, A., Kristiansen, K., and Jansen, J. (1950). Experimental demonstration of a pontine homologue in birds. J. Comp. Neurol. 92, 23-69.

Burns, S., and Wallman, J. (1981). Relation of single unit properties to the oculomotor function of the nucleus of the basal optic root (accessory optic system) in chickens. Exp. Brain Res. 42, 171-180.

Clarke, P. G. H. (1977). Some visual and other connections to the cerebellum of the pigeon. J. Comp. Neurol. 174, 535-552.

Collewijn, H. (1975). Direction-selective units in the rabbit's nucleus of the optic tract. Brain Res. 100, 489-508.

Crowder, N. A., Dawson, M. R. W., and Wylie, D. R. (2003). Temporal frequency and velocity-like tuning in the pigeon accessory optic system. J. Neuroph ysiol. 90, 1829-1841. doi: 10.1152/jn.00654.2002

Dakin, R., Fellows, T. K., and Altshuler, D. L. (2016). Visual guidance of forward flight in hummingbirds reveals control based on image features instead of pattern velocity. Proc. Natl. Acad. Sci. U.S.A. 113, 8849-8854. doi: 10.1073/pnas.1603221113

Davies, M. N. O., and Green, P. R. (1990). Optic flow-field variables trigger landing in hawk but not in pigeons. Naturwissenschaften 77, 142-144.

Eccles, J. C., Llinás, R., Sasaki, K., and Voorhoeve, P. E. (1966). Interaction experiments on the responses evoked in Purkinje cells by climbing fibres. $J$. Physiol. 182, 297-315.

Eckmeier, D., Geurten, B. R. H., Kress, D., Mertes, M., Kern, R., Egelhaaf, M., et al. (2008). Gaze strategy in the free flying zebra finch (Taeniopygia guttata). PLoS ONE 3:e3956. doi: 10.1371/journal.pone.0003956

Elder, D. M., Grossberg, S., and Mingolla, E. (2009). A neural model of visually guided steering, obstacle avoidance, and route selection. J. Exp. Psychol. Hum. Percept. Perform. 35, 1501-1531. doi: 10.1037/a0016459 that their [hummingbirds] habit of flying close to flowers in dense vegetation has tuned the hummingbird LM to its specific visual environment." Hummingbirds may, in fact, be an especially powerful group in which to gain a deeper understanding of the role that optic flow processing plays in flight behavior of birds.

\section{AUTHOR CONTRIBUTIONS}

All authors had full access to all of the data in the manuscript and take responsibility for the integrity of the data and the accuracy of the data analysis. Conceived and designed the manuscript: DW. Performed experiments and acquired data: CG-I, AI, and AG. Data analysis: CG-I, AI, and AG. Writing the manuscript: DW, CG-I, AI, and DA. Supervised the study: DW, DA, and AI.

\section{FUNDING}

Funding for this research was provided by NSERC to DW, DA, and AI.

Fan, T. X., Weber, A. E., Pickard, G. E., Faber, K. M., and Ariel, M. (1995). Visual responses and connectivity in the turtle pretectum. J. Neurophysiol. 73, 2507-2521. doi: 10.1152/jn.1995.73.6.2507

Feenders, G., Liedvogel, M., Rivas, M., Zapka, M., Horita, H., Hara, E., et al. (2008). Molecular mapping of movement-associated areas in the Avian brain: a motor theory for vocal learning origin. PLoS ONE 3:e1768. doi: 10.1371/journal.pone.0001768

Fite, K. V., Reiner, A., and Hunt, S. P. (1979). Optokinetic nystagmus and the accessory optic system of pigeon and turtle. Brain Behav. Evol. 16, 192-202.

Freedman, S. L., Feirabend, H. K., Vielvoye, G. J., and Voogd, J. (1975). Reexamination of the ponto-cerebellar projection in the adult white leghorn (Gallus domesticus). Acta Morphol. Neerl. Scand. 13, 236-238.

Frost, B. J., Wylie, D. R., and Wang, Y.-C. (1990). The processing of object and self-motion in the tectofugal and accessory optic pathways of birds. Vision Res. 30, 1677-1688.

Frost, B., and Nakayama, K. (1983). Single visual neurons code opposing motion independent of direction. Science 220, 744-745.

Gaede, A. H., Goller, B., Lam, J. P. M., Wylie, D. R., and Altshuler, D. L. (2017). Neurons responsive to global visual motion have unique tuning properties in hummingbirds. Curr. Biol. 27, 279-285. doi: 10.1016/j.cub.2016.11.041

Gamlin, P. D. R., and Cohen, D. H. (1988a). Projections of the retinorecipient pretectal nuclei in the pigeon (Columba livia). J. Comp. Neurol. 269, 18-46.

Gamlin, P. D. R., and Cohen, D. H. (1988b). Retinal projections to the pretectum in the pigeon (Columba livia). J. Comp. Neurol. 269, 1-17.

Gibson, J. J. (1954). The visual perception of objective motion and subjective movement. Psychol. Rev. 61, 304-314.

Gibson, J. J. (1979). The Ecological Approach to Visual Perception. Boston, MA: Houghton Mifflin.

Gioanni, H., Rey, J., Villalobos, J., and Dalbera, A. (1984). Single unit activity in the nucleus of the basal optic root (nBOR) during optokinetic, vestibular and visuo-vestibular stimulations in the alert pigeon (Columbia livia). Exp. Brain Res. 57, 49-60.

Gioanni, H., Rey, J., Villalobos, J., Richard, D., and Dalbera, A. (1983a). Optokinetic nystagmus in the pigeon (Columba livia) II. Role of the pretectal nucleus of the accessory optic system (AOS). Exp. Brain Res. 50-50, 237-247.

Gioanni, H., Villalobos, J., Rey, J., and Dalbera, A. (1983b). Optokinetic nystagmus in the pigeon (Columba livia) III. Role of the nucleus ectomamillaris (nEM): interactions in the accessory optic system (AOS). Exp. Brain Res. 50-50, 248-258.

Giolli, R. A., Blanks, R. H., and Lui, F. (2006). The accessory optic system: basic organization with an update on connectivity, neurochemistry, and function. Prog. Brain. Res. 151, 407-440. doi: 10.1016/S0079-6123(05)51013-6 
Goller, B., and Altshuler, D. L. (2014). Hummingbirds control hovering flight by stabilizing visual motion. Proc. Natl. Acad. Sci. U.S.A. 111, 18375-18380. doi: 10.1073/pnas.1415975111

Graf, W., Simpson, J. I., and Leonard, C. S. (1988). Spatial organization of visual messages of the rabbit's cerebellar flocculus. II. Complex and simple spike responses of Purkinje cells. J. Neurophysiol. 60, 2091-2121.

Graham, D. J., and Wylie, D. R. (2012). Zebrin-Immunopositive and -immunonegative stripe pairs represent functional units in the pigeon vestibulocerebellum. J. Neurosci. 32, 12769-12779. doi: 10.1523/JNEUROSCI.0197-12.2012

Gutiérrez-Ibáñez, C., Iwaniuk, A. N., Moore, B. A., Fernández-Juricic, E., Corfield, J. R., Krilow, J. M., et al. (2014). Mosaic and concerted evolution in the visual system of birds. PLoS ONE 9:e90102. doi: 10.1371/journal.pone.0090102

Gutierrez-Ibanez, C., Iwaniuk, A., and Wylie, D. (2017). Enlargement of telencephalic-cerebellar pathways in parrots: convergent evolution with primates? Brain. Behav. Evol. 89, 290. doi: 10.1159/000479204

Hellmann, B., Güntürkün, O., and Manns, M. (2004). Tectal mosaic: Organization of the descending tectal projections in comparison to the ascending tectofugal pathway in the pigeon. J. Comp. Neurol. 472, 395-410. doi: 10.1002/cne.20056

Hunt, S. P., and Künzle, H. (1976). Observations on the projections and intrinsic organization of the pigeon optic tectum: an autoradiographic study based on anterograde and retrograde, axonal and dendritic flow. J. Comp. Neurol. 170, $153-172$.

Husband, S., and Shimizu, T. (2001). "Evolution of the avian visual system," in Avian Visual Cognition, ed. R. G. Cook. Available online at: www.pigeon.psy. tufts.edu/avc/husband/.

Ibbotson, M. R. (2017). Visual neuroscience: unique neural system for flight stabilization in hummingbirds. Curr. Biol. 27, R58-R61. doi: $10.1016 /$ j.cub.2016.11.052

Ito, M. (1984). The Cerebellum and Neural Control. New York, NY: Raven press.

Ito, M. (1998). Cerebellar learning in the vestibulo-ocular reflex. Trends Cogn. Sci. 2, 313-321.

Iwaniuk, A. N., and Wylie, D. R. (2007). Neural specialization for hovering in hummingbirds: hypertrophy of the pretectal nucleus lentiformis mesencephali. J. Comp. Neurol. 500, 211-221. doi: 10.1002/cne.21098

Iwaniuk, A. N., Hurd, P. L., and Wylie, D. R. (2007). Comparative morphology of the Avian Cerebellum: II. size of Folia. Brain Behav. Evol. 69, 196-219. doi: $10.1159 / 000096987$

Jerison, H. J. (1973). Evolution of the Brain and Intelligence. New York, NY: Academic Press.

Karten, H. J., and Hodos, W. (1967). A Stereotaxic Atlas of the Brain of the Pigeon (Columbia livia). Baltimore, MD: Johns Hopkins Press.

Katte, O., and Hoffmann, K.-P. (1980). Direction specific neurons in the pretectum of the frog (Rana esculenta). J. Comp. Physiol. A 140, 53-57.

Konishi, M. (2003). Coding of auditory space. Annu. Rev. Neurosci. 26, 31-55. doi: 10.1146/annurev.neuro.26.041002.131123

Kornhuber, H. H. (1974). Cerebral cortex, cerebellum and basal ganglia: An introduction to their motor functions. Neuroscience Third Study Program, $267-280$.

Larsell, O. (1967). The Comparative Anatomy and Histology of the Cerebellum: From Myxinoids Through Birds. Minneapolis: University of Minnesota Press.

Lau, K. L., Glover, R. G., Linkenhoker, B., and Wylie, D. R. (1998). Topographical organization of inferior olive cells projecting to translation and rotation zones in the vestibulocerebellum of pigeons. Neuroscience 85, 605-614.

Lee, D. N. (1980). The optic flow field: the foundation of vision. Philos. Trans. $R$. Soc. Lond. B. Biol. Sci. 290, 169-79.

Lee, D. N., and Reddish, P. E. (1981). Plummeting gannets: a paradigm of ecological optics. Nature 293, 293-294.

Lee, D. N., Davies, M. N. O., Green, P. R., and (Ruud). Van Der Weel, F. R. (1993). Visual control of velocity of approach by pigeons when landing. J. Exp. Biol. $180,85-104$

Lee, D. N., Reddish, P. E., and Rand, D. T. (1991). Aerial docking by hummingbirds. Naturwissenschaften 78, 526-527.

Lesica, N. A., Lingner, A., and Grothe, B. (2010). Population coding of interaural time differences in gerbils and barn owls. J. Neurosci. 30, 11696-11702. doi: 10.1523/JNEUROSCI.0846-10.2010

Marín, G., Henny, P., Letelier, J. C., Sentis, E., Karten, H., Mrosko, B., et al. (2001). A simple method to microinject solid neural tracers into deep structures of the brain. J. Neurosci. Methods 106, 121-129. doi: 10.1016/S0165-0270(01) 00332-6

McKenna, O. C., and Wallman, J. (1985a). Accessory optic system and pretectum of birds: comparisons with those of other vertebrates. Brain. Behav. Evol. 26 , 91-116.

McKenna, O. C., and Wallman, J. (1985b). Functional postnatal changes in avian brain regions responsive to retinal slip: a 2-deoxy-D-glucose study. J. Neurosci. $5,330-342$.

Morgan, B., and Frost, B. J. (1981). Visual response characteristics of neurons in nucleus of basal optic root of pigeons. Exp. Brain Res. 42, 181-188.

Page, W. K., and Duffy, C. J. (2008). Cortical neuronal responses to optic flow are shaped by visual strategies for steering. Cereb. Cortex 18, 727-739.

Pakan, J. M. P., and Wylie, D. R. (2006). Two optic flow pathways from the pretectal nucleus lentiformis mesencephali to the cerebellum in pigeons (Columba livia). J. Comp. Neurol. 499, 732-744. doi: 10.1093/cercor/bhm109

Pakan, J. M. P., Graham, D. J., and Wylie, D. R. (2010). Organization of visual mossy fiber projections and zebrin expression in the pigeon vestibulocerebellum. J. Comp. Neurol. 518, 175-198. doi: 10.1002/cne.22192

Pakan, J. M. P., Graham, D. J., Iwaniuk, A. N., and Wylie, D. R. (2008). Differential projections from the vestibular nuclei to the flocculus and uvula-nodulus in pigeons (Columba livia). J. Comp. Neurol. 508, 402-417. doi: 10.1002/cne.21623

Pakan, J. M. P., Krueger, K., Kelcher, E., Cooper, S., Todd, K. G., and Wylie, D. R. (2006). Projections of the nucleus lentiformis mesencephali in pigeons (Columba livia): a comparison of the morphology and distribution of neurons with different efferent projections. J. Comp. Neurol. 495, 84-99. doi: 10.1002/cne.20855

Paulin, M. G. (1993). The role of the cerebellum in motor control and perception. Brain. Behav. Evol. 41, 39-50.

Ros, I. G., and Biewener, A. A. (2016). Optic flow stabilizes flight in ruby-throated hummingbirds. J. Exp. Biol. 219, 2443-2448. doi: 10.1242/jeb.128488

Schiffner, I., and Srinivasan, M. V. (2015). Direct evidence for vision-based control of flight speed in budgerigars. Sci. Rep. 5:10992. doi: 10.1038/srep10992

Sherry, D. F., Vaccarino, A. L., Buckenham, K., and Herz, R. S. (1989). The hippocampal complex of food-storing birds. Brain. Behav. Evol. 34, 308-317.

Simpson, J. I. (1984). The accessory optic system. Annu. Rev. Neurosci. 7, 13-41.

Striedter, G. F. (2005). Principles of Brain Evolution. Sunderland, MA: Sinauer.

Vega-Zuniga, T., Campos, L., Severin, D., Marin, G., Letelier, J., and Mpodozis, J. (2011). The avian ventral nucleus of the lateral Geniculate (GLv) has key role in the generation of visually guided gaze orientation movements. Society for Neuroscience Abstracts, Program No. 272.17.

Vega-Zuniga, T., Marín, G. J., González-Cabrera, C., Planitscher, E., Hartmann, A., Marks, V., et al. (2016). Microconnectomics of the pretectum and ventral thalamus in the chicken (Gallus gallus). J. Comp. Neurol. 524, 2208-2229. doi: 10.1002/cne. 23941

Vega-Zuniga, T., Mpodozis, J., Karten, H. J., Marín, G. J., Hain, S., and Luksch, H. (2014). Morphology, projection pattern, and neurochemical identity of Cajal's centrifugal neurons: The cells of origin of the tectoventrogeniculate pathway in pigeon (Columba livia) and chicken (Gallus gallus). J. Comp. Neurol. 522, 2377-2396. doi:10.1002/cne.23539

von Hardenberg, A., and Gonzalez-Voyer, A. (2013). Disentangling evolutionary cause-effect relationships with phylogenetic confirmatory path analysis. Evolution 67, 378-387. doi: 10.1111/j.1558-5646.2012.01790.x

Voogd, J., and Barmack, N. H. (2006). Oculomotor cerebellum. Prog. Brain Res. 151, 231-268. doi: 10.1016/s0079-6123(05)51008-2

Voogd, J., and Bigaré, F. (1980). "Topographical distribution of olivary and cortico nuclear fibres in the cerebellum: a review," in The Inferior Olivary Nucleus, eds J. Courville, C. de Montigny, and Y. Lamarre (New York, NY: Raven Press), 207-234.

Voogd, J., and Wylie, D. R. (2004). Functional and anatomical organization of floccular zones: a preserved feature in vertebrates. J. Comp. Neurol. 470, 107-112. doi:10.1002/cne.11022

Walsh, S. A., Iwaniuk, A. N., Knoll, M. A., Bourdon, E., Barrett, P. M., Milner, A. C., et al. (2013). Avian cerebellar floccular fossa size is not a proxy for flying ability in birds. PLoS ONE 8:e67176. doi:10.1371/journal.pone.0067176

Warren, W. H., Kay, B. A., Zosh, W. D., Duchon, A. P., and Sahuc, S. (2001). Optic flow is used to control human walking. Nat. Neurosci. 4, 213-216. doi: $10.1038 / 84054$ 
Winship, I. R., and Wylie, D. R. (2003). Zonal organization of the vestibulocerebellum in pigeons (Columba livia): I. Climbing fiber input to the flocculus. J. Comp. Neurol. 456, 127-139. doi: 10.1002/cne.10507

Winship, I. R., Hurd, P. L., and Wylie, D. R. (2005). Spatiotemporal tuning of optic flow inputs to the vestibulocerebellum in pigeons: differences between mossy and climbing fiber pathways. J. Neurophysiol. 93, 1266-1277. doi: $10.1152 /$ jn.00815.2004

Winterson, B. J., and Brauth, S. E. (1985). Direction-selective single units in the nucleus lentiformis mesencephali of the pigeon (Columba livia). Exp. brain Res. $60,215-26$.

Witmer, L. M., Chatterjee, S., Franzosa, J., and Rowe, T. (2003). Neuroanatomy of flying reptiles and implications for flight, posture and behaviour. Nature 425 , 950-953. doi: 10.1038/nature02048

Wylie, D. R. (2001). Projections from the nucleus of the basal optic root and nucleus lentiformis mesencephali to the inferior olive in pigeons (Columba livia). J. Comp. Neurol. 429, 502-513. doi: 10.1002/1096-9861(20010115)429:3<502::AID-CNE10>3.0.CO;2-E

Wylie, D. R., and Crowder, N. A. (2000). Spatiotemporal properties of fast and slow neurons in the pretectal nucleus lentiformis mesencephali in pigeons. J. Neurophysiol. 84, 2529-2540. doi: 10.1152/jn.2000.84.5.2529

Wylie, D. R., and Frost, B. J. (1990). The visual response properties of neurons in the nucleus of the basal optic root of the pigeon: a quantitative analysis. Exp. Brain Res. 82, 327-336.

Wylie, D. R., and Frost, B. J. (1991). Purkinje cells in the vestibulocerebellum of the pigeon respond best to either translational or rotational wholefield visual motion. Exp. Brain Res. 86, 229-232.

Wylie, D. R., and Frost, B. J. (1993). Responses of pigeon vestibulocerebellar neurons to optokinetic stimulation. II. the 3-dimensional reference frame of rotation neurons in the flocculus. J. Neurophysiol. 70, 2647-2659.

Wylie, D. R., and Frost, B. J. (1996). The pigeon optokinetic system - visual input in extraocular-muscle coordinates. Vis. Neurosci. 13, 945-953.
Wylie, D. R., Bischof, W. F., and Frost, B. J. (1998). Common reference frame for neural coding of translational and rotational optic flow. Nature 392, $278-282$.

Wylie, D. R., Gutierrez-Ibanez, C., Pakan, J. M. P., and Iwaniuk, A. N. (2009). The optic tectum of birds: mapping our way to understanding visual processing. Can. J. Exp. Psychol. Can. Psychol. Exp. 63, 328-338. doi: 10.1037/a00 16826

Wylie, D. R., Hoops, D., Aspden, J. W., and Iwaniuk, A. N. (2016). Zebrin II is expressed in sagittal stripes in the cerebellum of dragon lizards (Ctenophorus sp.). Brain Behav. Evol. 88, 177-186. doi: 10.1159/000452857

Wylie, D. R., Kripalani, T., and Frost, B. J. (1993). Responses of pigeon vestibulocerebellar neurons to optokinetic stimulation. I. functional organization of neurons discriminating between translational and rotational visual flow. J. Neurophysiol. 70, 2632-2646.

Wylie, D. R., Linkenhoker, B., and Lau, K. L. (1997). Projections of the nucleus of the basal optic root in pigeons (Columba livia) revealed with biotinylated dextran amine. J. Comp. Neurol. 384, 517-536.

Xiao, Q., and Frost, B. J. (2013). Motion parallax processing in pigeon (Columbo livia) pretectal neurons. Eur. J. Neurosci. 37, 1103-1111. doi: 10.1111/ejn.12115

Conflict of Interest Statement: The authors declare that the research was conducted in the absence of any commercial or financial relationships that could be construed as a potential conflict of interest.

Copyright (๑) 2018 Wylie, Gutiérrez-Ibáñez, Gaede, Altshuler and Iwaniuk. This is an open-access article distributed under the terms of the Creative Commons Attribution License (CC BY). The use, distribution or reproduction in other forums is permitted, provided the original author(s) and the copyright owner are credited and that the original publication in this journal is cited, in accordance with accepted academic practice. No use, distribution or reproduction is permitted which does not comply with these terms. 